\title{
Therapeutic impacts of Indian and Korean ginseng on human beings - a review
}

\section{R. Seenivasagam*}

Division of Drug Discovery and Development, Center of Molecular and Computational Biology, Department of Botany, St. Joseph College, P.B. 27094, 36, Langford Road,

Bangalore, Karnataka 560027, India

Fax: (+91) 4362-264120

E-mail: seenivasagam.pharma@gmail.com

*Corresponding author

\section{S. Sathiyamoorthy}

Korean Ginseng Center and Ginseng Genetic Resource Bank, Kyung Hee University,

Yongin, 449-701, South Korea

E-mail: sathiyamoorthybioinfo@gmail.com

\author{
K. Hemavathi \\ Department of Bioinformatics, \\ School of Chemical and Biotechnology, \\ SASTRA University, \\ Thanjavur-613 401, India \\ E-mail: hema.bioinfo@gmail.com
}

\begin{abstract}
Withania somnifera (Ashwagandha or Indian ginseng) is a small woody shrub or herb of the Solanaceae family. Ashwagandha is an herb which can compare favourably to the world's most renowned herbal tonics such as ginseng (Panax ginseng), astragalus (Astragalus membranaceus) and South American suma (Pfaffia paniculata). All these have been held in high regard for its ability to increase vitality, energy, endurance and stamina. Korean ginseng (Panax ginseng) is used in China as a preventative tonic to stimulate the entire body to overcome stress, fatigue and weakness. It contains 13 different ginsenosides. Panaxans help to lower blood sugar, polysaccharides work to enhance the immune system and its antioxidant properties are immune-stimulating to protect the body from disease and stress. It balances the release of stress hormones by supporting the organs that produce them. This article investigates the therapeutic and clinical effects of Indian and Korean ginseng.
\end{abstract}

Keywords: traditional medicine; cancer; immunology: medicinal plants; ginseng-alkaloids; herbal medicine; India; Korea. 
Reference to this paper should be made as follows: Seenivasagam, R., Sathiyamoorthy, S. and Hemavathi, K. (2011) 'Therapeutic impacts of Indian and Korean ginseng on human beings - a review', Int. J. Immunological Studies, Vol. 1, No. 3, pp.297-317.

Biographical notes: R. Seenivasagam graduated with M.Pharmacy from the Department of Pharmacoinformatics, SASTRA University, India. He has been researching in drug design, drug development and drug discovery through pharmacoinformatics and pharmacogenomics approach.

S. Sathiyamoorthy graduated with a $\mathrm{PhD}$ degree from the Department of Oriental Medicinal and Material Processing, Kyung Hee University, South Korea. His major research field is on systems biology and data mining.

K. Hemavathi graduated with an MSc degree from the Department of Bioinformatics, Bharathiar University, Coimbatore. She is a Lecturer at the School of Chemical and Biotechnology, SASTRA University, India. She is doing her research in computational biology and biocomputing.

\section{Introduction}

Withania somnifera and Panax ginseng are most important medicinal plants of Ayurveda and finds extensive significance in world traditional herbal preparations (Chaurasiya et al., 2009). The name 'somnifera' in Latin means 'sleep-inducer' which probably refers to its extensive use as a remedy against stress from a variety of daily chores. Some herbalists refer to ashwagandha as Indian ginseng, since it is used in India, in a way similar to how ginseng is used in traditional Chinese medicine to treat a large variety of human diseases. Ashwagandha is a shrub whose various parts (berries, leaves and roots) have been used by Ayurvedic practitioners as folk remedies, or as aphrodisiacs and diuretics (Ven Murthy et al., 2010). It is a traditional herbal medicine, used over 4,000 years in India, shown to have effect on neural growth and locomotive function. Although catecholamines and oxidative stress resulting in neurodegeneration and locomotive disorder are the main events in Parkinson's disease (PD), efficacy of the drug on these molecules and physiological abnormality are clear (RajaSankar et al., 2009). In Ayurveda, it is classified as a rasayana (rejuvenation) and expected to promote physical and mental health, rejuvenate the body in debilitated conditions and increase longevity. Having wide range of activity, it is used to treat almost all disorders that affect the human health. The present review discusses the pharmacological basis of the use of $W$. somnifera in various central nervous system (CNS) disorders, particularly its indication in epilepsy, stress and neurodegenerative diseases such as Parkinson's and Alzheimer's disorders, tardive dyskinesia, cerebral ischemia and even in the management of drug addiction (Kulkarni and Dhir, 2008).

Panax ginseng is traditionally associated with stimulating sexual function and increasing energy. Red ginseng is always produced from cultivated roots, usually from either South Korea or China. Red ginseng has been heated through steaming. It is frequently marinated in an herbal brew which results in the root becoming extremely brittle. Panax ginseng is available in four forms: 
1 fresh ginseng (FG)

2 white ginseng (WG)

3 red ginseng

4 sun ginseng (SG).

In 2002, a preliminary double-blind, crossover study of Korean red ginseng's effects on impotence reported that it can be an effective alternative for treating male erectile dysfunction. A total of 45 patients with clinically diagnosed erectile dysfunction were enrolled in a double-blind, placebo controlled, crossover study (eight weeks on treatment, two weeks of washout and eight weeks on treatment) in which the effects of Korean red ginseng and a vehicle placebo were compared using multiple variables. The ginseng dose was $900 \mathrm{mg}$. three times daily. Mean International Index of Erectile Function scores were significantly higher in patients treated with Korean red ginseng than in those who received placebo (baseline $28.0+/-16.7$ and $38.1+/-16.6$ versus $30.9+/-15.7$, $p<0.01$ ). Scores on questions three (penetration) and four (maintenance) were significantly higher in the ginseng than in the placebo group $(p<0.01)$. In response to the global efficacy question $60 \%$ of the patients answered that Korean red ginseng improved erection $(p<0.01)$. Among other variables penile tip rigidity on RigiScan showed significant improvement for ginseng versus placebo (Hong et al., 2002). A study shows that red ginseng reduces the relapse of gastric cancer versus control (Suh et al., 2002). A research of ginseng's effects on rats show that while both WG and red ginseng reduce the incidence of cancer, the effects appear to be greater with red ginseng (Yun et al., 2001). A study by Sung, H., Jung, Y.S. and Cho, Y.K. shows potentially beneficial effects of a combination of Korean red ginseng and highly active antiretroviral therapy in HIV-1-Infected patients. Falcarinol, a 17-carbon diyne fatty alcohol was isolated from carrot and red ginseng, shown to have potent anticancer properties on primary mammary epithelial (breast cancer) cells. Other acetylenic fatty alcohols in ginseng (panaxacol, panaxydol, panaxytriol) have antibiotic properties (http://www.cvi.asm.org/ cgi/content/abstract/CVI.00013-09v1).

\section{Withania somnifera}

\subsection{Clinical benefits}

Ashwagandha role in brain chemicals are:

1 GABA-mimetic activity having anxiolytic effect (Schliebs et al., 1997)

2 inhibiting cholinesterase and thereby retaining acetylcholine for longer time (Schliebs et al., 1997)

3 slowing down of tolerance of the analgesic effects of morphine

4 induction of axon and dendrite outgrowth and resulting in neuritis regeneration and synaptic reconstruction. 
Withania is an immunity boosting herb as:

1 immunity stimulating effect through macrophages (Iuvone et al., 2003)

2 raised antibody titre against Bordetella pertusis strains (responsible for diphtheria)

3 protective effect in cyclophosphamide induced myelosuppression (Iuvone et al., 2003)

4 beneficial in ageing and copper induced lipid preoxidation

5 Withania somnifera helping in chronic fatigue syndrome.

Ashwagandha as adaptogenic and anti-stress herb:

1 comparative to ginseng in chronic stress models

2 protective effect in stress induced neuronal degeneration (Schliebs et al., 1997)

3 helping to achieve better state to fight against stress (Grandhi et al., 1994; Singh et al., 2003; Hong et al., 2002; Ichikawa et al., 2006)

4 preventing stress related ulcer.

Ashwagandha is an herbal rejuvenative and reproductive which aids as:

1 as a great rejuvenative herb in ayurvedic medicine

2 beneficial in degenerative disorders like arthritis, diabetes and hypertension (Ichikawa et al., 2006)

3 it is a potent inhibitor of angiogenesis and it has the potential in cancer prevention and treatment (Ichikawa et al., 2006)

4 increasing libido and sexual function (Muruganandam et al., 2002)

5 increasing the sperm count

6 supporting female reproductive system with increase in ovarian weight and increased folliculogenesis (Muruganandam et al., 2002).

Ashwagandha offering a potential role in cancer therapy as:

1 anti-carcinogenic activity (Ichikawa et al., 2006)

2 growth inhibition of human tumour cell lines (Ichikawa et al., 2006; Iuvone et al., 2003)

3 counteracting mutagenic effect (Ichikawa et al., 2006)

4 Withania somnifera possessing anti-proliferative properties (Ichikawa et al., 2006)

5 as a natural source of potent radiosensitiser or chemotherapeutic agent

6 useful in ascitic sarcoma

7 useful in melanoma induced metastasis (Ichikawa et al., 2006)

8 supportive in skin carcinoma in rats 
9 supports DMBA induced squamous cell carcinoma

10 enhancing cellular immune response to mitogens

11 reversing paclitaxel induced neutropenia

12 anti-granuloma, anti-oxidative and chemoprotective activity.

Ashwagandha in Parkinson's and Alzheimer's disease:

1 presence of L-dopa in a herbal formulation with WS

2 cognition enhancing and memory improving activity through cholinergic channels (Muruganandam et al., 2002; Schliebs et al., 1997)

3 mood stabiliser, learning enhancement and memory retention (Schliebs et al., 1997).

Ashwagandha as free radical scavenger and antioxidant:

1 increasing the three natural antioxidants in rat's brain

2 immunostimulation through nitric oxide (NO) production in macrophage (Iuvone et al., 2003)

3 dose dependent free radical scavenging and protective effect on DNA cleavage

4 useful in iron overload and lead toxicity

5 preventing neuroleptic induced extra pyramidal side effects.

Ashwagandha as one of the best herbal remedies for anxiety and depression:

1 Withania somnifera is one of the best herbal remedies for anxiety and depression (Muruganandam et al., 2002)

2 anxiolytic effect comparable to lorazepam

3 antidepressant effect comparable to imipramine

4 found non-toxic in doses up to $100 \mathrm{mg}$ per $\mathrm{kg}$ of body weight

5 as calming, anticonvulsant and antispasmodic effect (Muruganandam et al., 2002)

6 capacity to stimulate thyroid function in female mice.

Cardiovascular and diabetic protection with ashwagandha:

1 cardio-protection against ischemic and reperfusion injury

2 beneficial in focal ischemia

3 supports anti-atherogenic activity in polyherbal formula

4 mild hypoglycemic, diuretic and anti-hypercholesterolemic effect

5 supportive in streptozotocin induced diabetes

6 supportive in diabetes induced cataract

7 supports diabetes induced oxidative damage in brain with aloe vera. 
Miscellaneous effects of ashwagandha:

1 anti-inflammatory activity in Withania somnifera (Ichikawa et al., 2006)

2 anti-viral and antibacterial activity

3 curing the side effects of one fungicide

4 protective effect in $\mathrm{CCl} 4$ induced hepatotoxicity

5 restoration of absorption of glucose in Jejunum similar to anti-inflammatory drug oxyphenbutazone

6 antiulcer activity (Singh et al., 2001).

Ashwagandha also using as:

1 antioxidant and free radical scavenger

2 body building aid

3 for weakness, fatigue, herbal rejuvenation, aphrodisiac (Iuvone et al., 2003; Schliebs et al., 1997)

4 nervine tonic, calming and anti-stress agent and adaptogenic herb (Grandhi et al., 1994; Singh et al., 2003)

5 visit ashwagandha related pages on holistic-herbalist to get more information

6 take one vegiacap twice or thrice a day, each vegicap contains ashwagandha $(5: 1)$ $500 \mathrm{mg}$, i.e., equivalent to $2.5 \mathrm{gm}$ of crude Withania somnifera.

\subsection{Active constituents}

The main constituents of ashwagandha are alkaloids and steroidal lactones. Biochemically heterogeneous alkaloids including cuscohygrine, anahygrine, tropine, pseudotropine, anaferine. The plant has steroidal lactones - withanolides (Ahuja et al., 2009; Murthy et al., 2008), withaferin, which are estrogenic compounds. Long considered a premier adaptogenic herb, Ashwagandha has clearly demonstrated anti-stress properties, including resistance to gastric ulcers caused by aspirin and improved endurance as measured by swimming times and other endurance tests. The chief active ingredients are glycowithanolides, which are potent immunomodulators. Researchers in India and Germany have shown Ashwagandha to be superior to Panax ginseng in double-blind trials controlled with placebos. Ashwagandha has been traditionally used as an aphrodisiac and treatment of impotence. Withaferin A is a major active constituent (Figure 1), in Ashwagandha and it was reported to have anti-carcinogenic effects in animal and cell cultures by decreasing the expression of nuclear factor-kappa B, suppressing intercellular tumour necrosis factor, and potentiating apoptotic signalling in cancerous cell lines (Ichikawa et al., 2006). There are few listed side effects for Withania somnifera in humans, but a study on its effects on rats found unfavourable issues in their hearts and adrenal glands in extremely high dosages taken for duration of 180 days (http://www.drugs.com/npp/ashwaganda.html). Withania somnifera stimulates the thyroid leading to thyrotoxicosis in some humans and in mice (Panda and Kar, 1998, 1999). 
Figure 1 Primary structure of Withaferin A (see online version for colours)

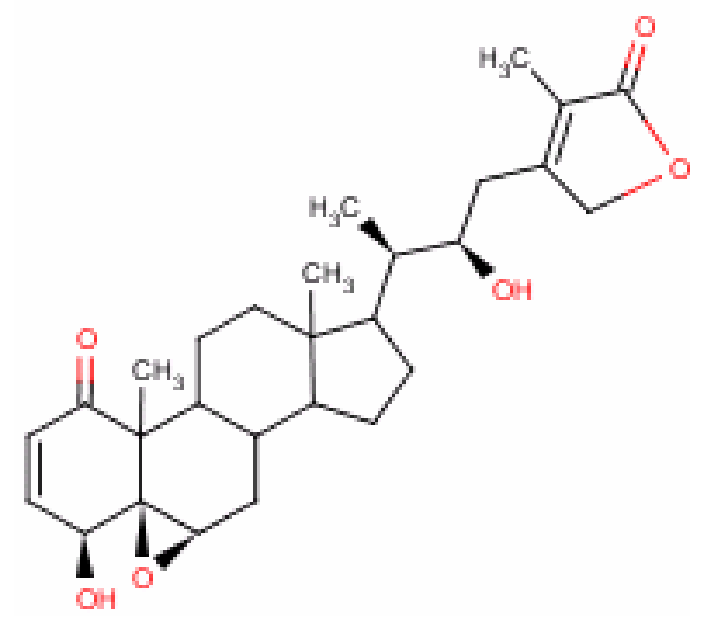

\section{Panax ginseng}

\subsection{Clinical benefits}

Panax ginseng as one of the best herbal remedies for:

1 physical restorative and preventative tonic for health and illness prevention

2 healthy for heart and good circulation

3 normalises blood pressure

4 reduces cholesterol

5 lowers blood sugar

6 helps to prevent arteriosclerosis

7 improves vision and hearing activity

8 improves working ability and energises physically and mentally

9 checks irritability, stress and is good for depression (Lin et al., 2009)

10 sexual stimulant, enhances sexual desire and improves impotency and low sperm count

11 improves athletic performance and increases endurance and stamina

12 helps with the discomforts of menopause

13 may inhibit tumour growth, good cancer preventative effects (Bi et al., 2009; Yun et al., 2010). 
People who are pregnant or taking MAO inhibitor drugs should not use this herb. Korean ginseng is very stimulating so it should be taken early in the day. High dosages could make some jittery. Check with your doctor before taking if you have high blood pressure. In rare cases, postmenopausal women may experience vaginal bleeding due to its mildly estrogenic effect. If this happens, let your doctor know you are taking Korean ginseng so this won't be mistaken for a sign of uterine cancer.

\subsection{Active constituents}

The major pharmacologically active constituents of ginsengs are ginsenosides, which can be mainly classified as protopanaxadiol (PPD) and protopanaxatriol (PPT) groups. The various steaming temperature and time treatment of the ginseng herbs can change ginsenoside profiles, and enhance their anti-cancer activities. This heat treatment process may increase the role of ginseng in treating colorectal cancer (Wang and Yuan, 2008). The aglycone of PP ginsenoside was discovered and reported, having the conspicuous anti-cancer activity for the first time from the fruits of Panax ginseng (Liu et al., 2009). The puffing process was evaluated as an alternative to the steaming process for producing a biologically more active ginseng product, like red ginseng, from raw ginseng. A puffing treatment of dried raw ginseng roots induced an overall increase in crude saponin content. As puffing pressure increased, the content of ginsenoside Re, Rg1, Rb1, Rc, and Rb2 decreased, while ginsenoside Rg3 increased significantly as compared to raw ginseng. The content of ginsenoside $\mathrm{Rg} 3$ in puffed ginseng at a pressure of $490 \mathrm{kPa}$ was similar to that of red ginseng. Cancer cell lines (HeLa, MCF-7, and HepG2) showed that antiproliferative effects of saponin extract of puffed ginseng increased with an increase in puffing pressure. Ginseng explosively puffed at $490 \mathrm{kPa}$ had similar saponin constituents and antiproliferative effects as those of red ginseng (Yoon et al., 2010). Pretreatment of $\mathrm{NCI}-\mathrm{H} 460$ human lung cancer cells with a metabolite of ginseng saponin (compound $\mathrm{K}$ ) (Figure 2) produced by intestinal bacteria enhances gamma-ray radiation-induced cell death. Increases in apoptosis induced by combined treatment are made apparent in the observation of nuclear fragmentation, loss of mitochondrial membrane potential (Deltapsi), and activation of caspase 3. Apoptosis induced by compound $\mathrm{K}$ and gamma-ray radiation is associated with reactive oxygen species (ROS) generation. Furthermore, compound $\mathrm{K}$, in combination with gamma-ray radiation, has an enhanced effect in the regression of NCI-H460 tumour xenografts of nude mice. These results suggest that compound $\mathrm{K}$ has possible application for cancer therapy when used in combination with gamma-ray radiation (Chae et al., 2009). PPT is a nutraceutical-based active constituent of Korean red ginseng and is reported to exhibit potent anti-tumour properties. Its activity may be in part due to its induction of phase 2 chemoprotective enzymes. Its unique properties may have important implications in cancer therapeutics ( $\mathrm{Ng}$ et al., 2008). 20(S)-25-methoxyl-dammarane-3 beta, 12 beta, 20-triol (25-OCH (3)-PPD), a newly identified natural product from Panax notoginseng, exhibits activity against a variety of cancer cells. The effects of this compound on human A549, H358, and H838 lung cancer cells and compare these effects with a control lung epithelial cell line, BEAS-2B. 25-OCH (3)-PPD decreased survival, inhibited proliferation, and induced 
apoptosis and G1 cell cycle arrest in the lung cancer cell lines. The P. notoginseng compound also decreased the levels of proteins associated with cell proliferation and cell survival. Moreover, 25-OCH (3)-PPD inhibited the growth of A549 lung cancer xenograft tumors. 25-OCH (3)-PPD demonstrated low toxicity to non-cancer cells and no significant toxicity was seen when the compound was administered to animals. In conclusion, the preclinical data indicate that $25-\mathrm{OCH}$ (3)-PPD is a potential therapeutic agent in vitro and in vivo, and further preclinical and clinical development of this agent for lung cancer is warranted (Wang et al., 2009).

Figure 2 Primary structure of compound K (see online version for colours)

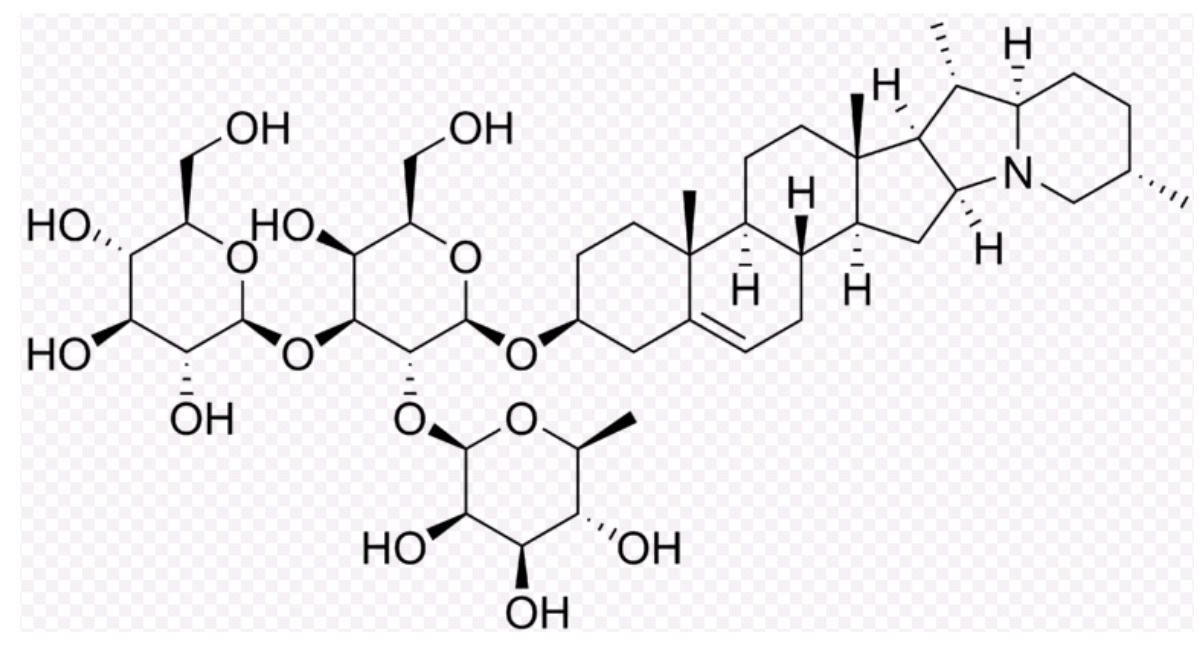

\subsection{Genetic influences on plant disease}

Polygalacturonase inhibiting proteins (PGIPs) are the major defence proteins which play an important role in resistance to infection of pathogens. A putative novel gene encoding PGIP was isolated from Panax ginseng C.A. Meyer, which shows $70.3 \%$ and $68.4 \%$ homology with chick pea and Arabidopsis PGIPs. The RACE PCR was preformed to isolate the full-length PGIP cDNA from Panax ginseng (Sathiyamoorthy et al., 2010b; Sathiyaraj et al., 2010; Wang et al., 2010). A full-length sequence (PgPR10-2) of the most abundant transcript from 14-year old ginseng EST library was isolated and cloned. PgPR10-2 gene encodes 465 bp open reading frame and its deduced protein contains 155 amino acids. Genomic DNA sequence reveals it contains two exons interrupted by one intron (Parvin et al., 2010; Sathiyamoorthy et al., 2010a). Expression of PgPR10-2 gene was especially abundant in roots and its transcripts showed differentially upregulated patterns against several given pathogens and abiotic stimuli. Observed enhanced ribonuclease activity and antifungal activity from tobacco transgenic lines suggest that the possible involvement of PgPR10-2 in defence-related mechanism via ribonuclease activity against biotic and abiotic stresses (Kim et al., 2009). 


\section{Comparative studies in clinical trials and therapeutic analysis}

Table 1 Comparative analysis of Indian and Korean ginseng

\begin{tabular}{|c|c|c|}
\hline $\begin{array}{l}\text { Therapeutic } \\
\text { effects }\end{array}$ & Indian ginseng & Korean ginseng \\
\hline $\begin{array}{l}\text { Anti-cancer } \\
\text { activity }\end{array}$ & $\begin{array}{l}\text { Efforts to prevent colon cancer have } \\
\text { targeted early detection through } \\
\text { screening and chemoprevention. In } \\
\text { the ginseng experiments groups of } 10 \\
\text { F344 rats were fed ginseng powder at } \\
\text { a dose of } 0.5 \mathrm{~g} / \mathrm{kg} \text { or } 2 \mathrm{mg} / \mathrm{kg} \text { for five } \\
\text { weeks. During weeks } 2 \mathrm{and} 3 \text { rats } \\
\text { were injected with } 10 \mathrm{mg} / \mathrm{kg} \\
\text { azoxymethane to induce ACF. } \\
\text { Controls ( } n=10 \text { ) did not receive } \\
\text { azoxymethane (AOM). Rats were } \\
\text { killed by } \mathrm{CO}_{2} \text { overdose and ACF } \\
\text { counted in the rat colon. In eight } \\
\text { week post-initiation experiments } \\
\text { ginseng powder inhibited the } \\
\text { progression of established ACF, } \\
\text { indicating a cytostatic effect. This } \\
\text { may be due to an anti-inflammatory } \\
\text { effect. } \\
\text { There is a body of literature that } \\
\text { suggests that compounds in wine, } \\
\text { tumeric, and tea inhibit } \\
\text { cyclooxygenases, thus reducing } \\
\text { prostaglandin-mediated effects on the } \\
\text { colon. As colon tumors have been } \\
\text { shown to highly express COX-2 } \\
\text { protein, and given, that many NSAID } \\
\text { drugs also suppress COX-1, it is } \\
\text { tempting to speculate that herbal } \\
\text { products that inhibit one or both } \\
\text { forms of the COX enzyme will be } \\
\text { effective agents for the prevention of } \\
\text { cancer in man (Wargovich, } 2001 \text { ). }\end{array}$ & 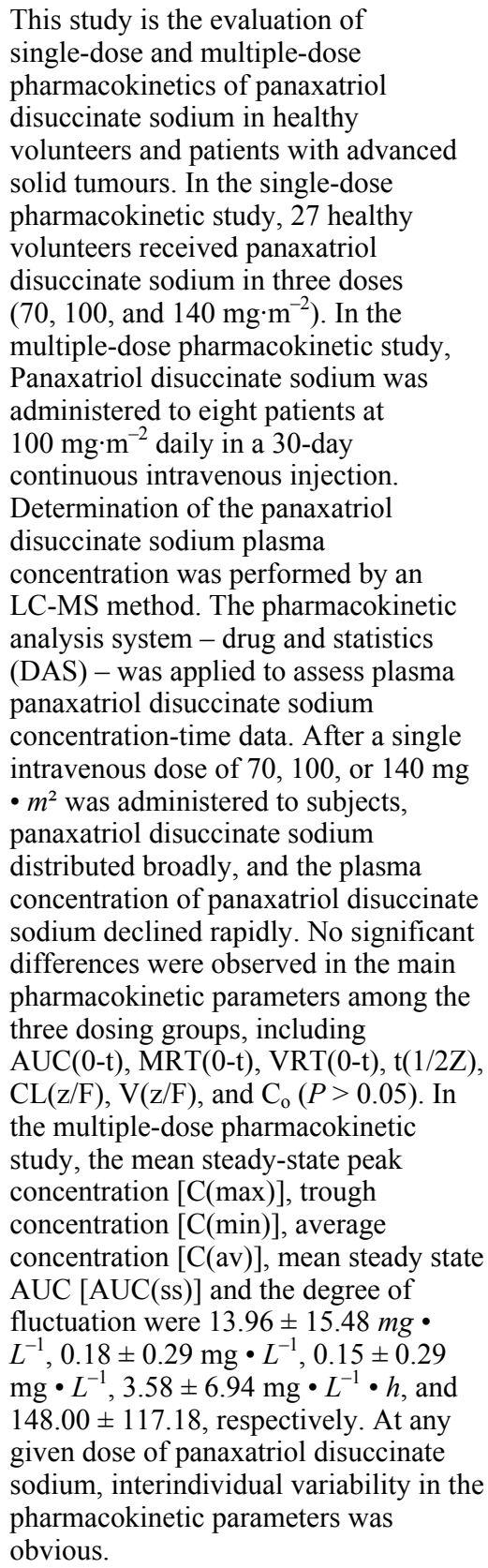 \\
\hline
\end{tabular}


Table 1 Comparative analysis of Indian and Korean ginseng (continued)

\begin{tabular}{|c|c|c|}
\hline $\begin{array}{l}\text { Therapeutic } \\
\text { effects }\end{array}$ & Indian ginseng & Korean ginseng \\
\hline $\begin{array}{l}\text { Anti-cancer } \\
\text { activity }\end{array}$ & & $\begin{array}{l}\text { The effect of the dose level on } \\
\text { single-dose pharmacokinetics of } \\
\text { panaxatriol disuccinate sodium was not } \\
\text { significant. No accumulation was } \\
\text { observed with exposure to } 100 \mathrm{mg} \cdot \mathrm{m}^{-2} \\
\text { panaxatriol disuccinate sodium in the } \\
\text { 30-day continuous intravenous } \\
\text { injection. All subjects were evaluated } \\
\text { for tolerability throughout the study. } \\
\text { Thus, the phase II dose of panaxatriol } \\
\text { disuccinate sodium may be considered } \\
\text { to be } 100 \mathrm{mg} \cdot \mathrm{m}^{-2} \text { for a } 30 \text {-day } \\
\text { continuous intravenous injection to treat } \\
\text { patients with advanced solid tumors } \\
\text { (Yan et al., 2010). }\end{array}$ \\
\hline $\begin{array}{l}\text { In gastric } \\
\text { ulcers }\end{array}$ & $\begin{array}{l}\text { A new withanolide-free aqueous } \\
\text { fraction was isolated from the roots } \\
\text { of this plant and was evaluated for } \\
\text { putative anti-stress activity against } \\
\text { swimming induced gastric ulceration } \\
\text { and hypothermia, immobilisation } \\
\text { induced gastric ulceration, auto } \\
\text { analgesia and biochemical changes } \\
\text { in the adrenal glands (Singh et al., } \\
\text { 2001). }\end{array}$ & $\begin{array}{l}\text { An acidic polysaccharide fraction, } \\
\text { GRA-4, of the root extract of Panax } \\
\text { ginseng, when administered from } 50 \text { to } \\
200 \mathrm{mg} / \mathrm{kg} \text { orally, inhibited gastric } \\
\text { lesions induced by } \mathrm{HCl} \text {-ethanol or } \\
\text { absolute ethanol, in a dose-dependent } \\
\text { manner. The cytoprotective activity of } \\
\text { GRA-4 decreased after its treatment } \\
\text { with period date but not after protein } \\
\text { digestion, indicating that the } \\
\text { carbohydrate moiety of this acidic } \\
\text { polysaccharide contributes to this } \\
\text { activity (Sun et al., 1991). }\end{array}$ \\
\hline $\begin{array}{l}\text { In CNS } \\
\text { diseases }\end{array}$ & $\begin{array}{l}\text { Withania somnifera root extract } \\
\text { (Ws)/Ashwagandha/Indian ginseng is } \\
\text { a traditional herbal medicine, used } \\
\text { over } 4,000 \text { years in India, shown to } \\
\text { have effect on neural growth and } \\
\text { locomotor function. Although } \\
\text { catecholamines and oxidative stress } \\
\text { resulting in neurodegeneration and } \\
\text { locomotor disorder are the main } \\
\text { events in Parkinson's disease (PD), } \\
\text { efficacy of the drug on these } \\
\text { molecules and physiological } \\
\text { abnormality are not clear. The } \\
\text { objective of the study was to examine } \\
\text { effect of Ws on catecholamines and } \\
\text { physiological abnormalities seen in } \\
\text { PD using PD model mouse. Mouse } \\
\text { were treated with 1-methyl-4-phenyl- } \\
1,2,3,6 \text {-tetrahydropyridine (MPTP) } \\
\text { for four days to show biochemical } \\
\text { and physiological abnormalities } \\
\text { similar to patients with PD. }\end{array}$ & $\begin{array}{l}\text { Transplantation of olfactory } \\
\text { ensheathing cells (OECs) is currently } \\
\text { considered to be one of the most } \\
\text { promising repair strategies for human } \\
\text { spinal cord injury. However, the factors } \\
\text { that regulate OECs are still poorly } \\
\text { understood. Ginsenoside Rg1 (Rg1), the } \\
\text { phytosteriol from Panax ginseng, is a } \\
\text { potent neuro protective agent that } \\
\text { promotes axonal regeneration. The aim } \\
\text { of this study is to determine whether } \\
\text { Rg1 would influence the biological } \\
\text { activity of OECs. Primary cultured } \\
\text { OECs from the olfactory bulb of } \\
\text { neonatal rats were treated with Rg1 of } \\
\text { various concentrations and durations. } \\
\text { Using MTT and bromodeoxyuridine } \\
\text { assays, we found that Rg1 significantly } \\
\text { promoted cell proliferation, with an } \\
\text { optimal concentration of } 40 \text { mug/ml of } \\
\text { Rg1 at } 72 \text { h. }\end{array}$ \\
\hline
\end{tabular}


Table 1 Comparative analysis of Indian and Korean ginseng (continued)

\begin{tabular}{|c|c|c|}
\hline $\begin{array}{l}\text { Therapeutic } \\
\text { effects }\end{array}$ & Indian ginseng & Korean ginseng \\
\hline $\begin{array}{l}\text { In CNS } \\
\text { diseases }\end{array}$ & $\begin{array}{l}\text { PD mice were treated with Ws } \\
100 \mathrm{mg} / \mathrm{kg} \text { body weight for seven or } \\
28 \text { days. Catecholamines: dopamine } \\
\text { (DA), 3, 4-dihydroxy-phenylacetic } \\
\text { acid (DOPAC) and homovanillic acid } \\
\text { (HVA); antioxidants: glutathione } \\
\text { (GSH) and glutathione peroxidase } \\
\text { (GPx); and lipid peroxidation marker } \\
\text { (TBARS) were analysed in the Ws } \\
\text { treated and untreated PD mouse } \\
\text { striatum. Mouse treated with MPTP } \\
\text { showed reduced levels of DA, } \\
\text { DOPAC, HVA, GSH and GPx and } \\
\text { induced thiobarbituric acid reactive } \\
\text { substance (TBARS) level compared } \\
\text { to the control. Physiological } \\
\text { abnormalities were seen in the mouse } \\
\text { as determined by hang test and } \\
\text { rotarod test. Oral treatment of PD } \\
\text { mouse Ws root extract (100mg/kg } \\
\text { body weight) for } 7 \text { days or } 28 \text { days } \\
\text { increased DA, DOPAC and HVA } \\
\text { levels and normalised TBARS levels } \\
\text { in the corpus striatum of the PD } \\
\text { mouse. The } 7 \text { days Ws treated mice } \\
\text { showed improved motor function as } \\
\text { determined by hang test and rotarod } \\
\text { test. Treatment with Ws for } 28 \text { days } \\
\text { increased GSH and GPx levels in the } \\
\text { striatum compared to the Ws } \\
\text { untreated PD mouse striatum. These } \\
\text { data suggest that Ws is a potential } \\
\text { drug in treating catecholamines, } \\
\text { oxidative damage and physiological } \\
\text { abnormalities seen in the PD mouse } \\
\text { (RajaSankar et al., } 2009 \text { ). }\end{array}$ & $\begin{array}{l}\text { In addition, RT-PCR and ELISA assays } \\
\text { showed that Rg1 could upregulate the } \\
\text { mRNA expression and secretion of glial } \\
\text { cell-derived neurotrophic factor, brain- } \\
\text { derived neurotrophic factor, and nerve } \\
\text { growth factor. These results suggest that } \\
\text { Rg1 may have a great potential in OEC } \\
\text { therapy (Lu et al., 2010). }\end{array}$ \\
\hline In arthritis & $\begin{array}{l}\text { The plant Withania somnifera Dunal } \\
\text { (Ashwagandha), is widely used in the } \\
\text { Ayurvedic system of medicine to } \\
\text { treat arthritis (Ichikawa et al., 2006). }\end{array}$ & $\begin{array}{l}\text { This study explain the therapeutic effect } \\
\text { and possible mechanism of total Panax } \\
\text { notoginseng saponins (PNS) for } \\
\text { treatment of rheumatoid arthritis (RA), } \\
\text { and to observe its safety and influence } \\
\text { on RA immune related inner } \\
\text { environment. Eighty-four patients were } \\
\text { randomly assigned to two groups. All } \\
\text { were treated with the routine therapy } \\
\text { with diclofenac sodium, Leflunomide } \\
\text { and prednisone, but for the } 43 \text { patients } \\
\text { in the treatment group PNS was given } \\
\text { additionally. The therapeutic course was } \\
28 \text { days for both groups. }\end{array}$ \\
\hline
\end{tabular}


Table 1 Comparative analysis of Indian and Korean ginseng (continued)

\begin{tabular}{lll}
\hline $\begin{array}{l}\text { Therapeutic } \\
\text { effects }\end{array}$ & Indian ginseng & Korean ginseng
\end{tabular}

In arthritis

Anti-diabetic activity
Ginseng polysaccharides (GH1) 50 to $200 \mathrm{mg} / \mathrm{kg}$ ip or sc reduced blood glucose and liver glycogen of mice. Adrenalectomy did not affect this action. GH1 increased the content of pyruvic acid, but decreased the content of lactic acid by weakening the activity of lactate dehydrogenase. GH1 accelerated oxidativephosphorylation of carbohydrate since the activities of succinate dehydrogenase (SDH) and cytochrome oxidase (CCO) were obviously stimulated. Besides the promotion of the activity of SDH in human embryonic lung fibroblasts (HELF), GH1 decreased the content of polysaccharides in HELF of the 24th age generation, but increased that of the 40th age generation. On the other hand, GH1 stimulated the release of insulin.
Clinical efficacy and change of indexes including platelet counts, immnuoglobulins (IgG, IgA, IgM), complement $(\mathrm{C}) 3$, rheumatoid factor (RF), C-reactive protein (CRP), ceruloplasmin (CER), haptoglobin (HPT), and alpha1-acid glycoprotein (AAG) were observed. Significant improvement of clinical symptoms, including the joint swelling index, joint tenderness index, joint pain index, time of morning stiffness and VAS revealed in both groups after treatment, and the effect in the treatment group was better $(P<0.05$ or $P<0.01)$. PLT, CER, AAG, HPT, CRP, IgG, IgA, IgM, C3 and RF were lowered in both groups $(P<0.01)$, but the lowering in PLT, CER, AAG and CRP in the treatment group was more significant than that in the control group respectively $(P<0.05$ or $P<0.01)$. PNS can significantly improve the condition of patients; enhance the therapeutic effect in treating RA, through regulating the disordered immunity and improving the effect of anti-inflammatory and analgesia (Zhang et al., 2007).

Panax ginseng and its major component, ginsenosides, are widely used for the prevention of various disorders in oriental medicine. To evaluate the effect of ginsenoside Rc (Rc), one of the active constituents in Panax ginseng, on glucose uptake in C2C12 myotubes. Treatment of the $\mathrm{C} 2 \mathrm{C} 12$ myotubes with Re significantly increased glucose uptake. To determine the mechanism of Rc-induced glucose uptake, either insulin-dependent signalling or insulin-independent signalling pathway activities were measured using western blot analysis. We showed that Rc significantly activated an insulin-independent AMPK signalling pathway. However, Rc had no effect on the components of the insulin-dependent signalling pathway, such as receptor substrates (IRS)-1 and protein kinase B or Akt (PKB/Akt). 
Table 1 Comparative analysis of Indian and Korean ginseng (continued)

\begin{tabular}{|c|c|c|}
\hline $\begin{array}{l}\text { Therapeutic } \\
\text { effects }\end{array}$ & Indian ginseng & Korean ginseng \\
\hline $\begin{array}{l}\text { Anti-diabetic } \\
\text { activity }\end{array}$ & $\begin{array}{l}\text { It is suggested that the reduction of } \\
\text { blood glucose and liver glycogen } \\
\text { induced by GH1 be primarily due to } \\
\text { the increase of carbohydrate } \\
\text { utilisation and the decrease of } \\
\text { glycogenesis (Yang et al., 1990). }\end{array}$ & $\begin{array}{l}\text { Moreover, we found that treatment with } \\
\text { an AMPK inhibitor abolished both } \\
\text { glucose uptake and p38 MAPK } \\
\text { phosphorylation. } \\
\text { This result implies that AMPK activity } \\
\text { is critical for the Rc-induced glucose } \\
\text { uptake and that AMPK is situated } \\
\text { upstream of p38 MAPK. In addition, we } \\
\text { also showed that the activation of } \\
\text { AMPK and p38 induced by ginsenoside } \\
\text { Rc is mediated by reactive oxygen } \\
\text { species (ROS) production, suggesting } \\
\text { that upstream regulators of AMPK- and } \\
\text { p38 MAPK-mediated glucose uptake. } \\
\text { Ginsenoside Rc significantly enhances } \\
\text { glucose uptake by inducing ROS } \\
\text { generation, which leads to AMPK and } \\
\text { p38 MAPK activation. Consequently, } \\
\text { ginsenoside Rc can be used as a potent } \\
\text { natural anti-diabetic agent (Lee et al., } \\
2010 \text { ). }\end{array}$ \\
\hline
\end{tabular}

Anti-fungal Indian pseudoginseng saponins were activity

found to exhibit better activity than the Korean ginseng saponins in several tests employed including anti-fungal effect. The results indicate a need for in-depth study of Indian pseudoginseng as an adaptogenic agent, after cultivation of the plant under controlled conditions (Dua et al., 1989).
From the roots of the Chinese ginseng Panax ginseng a protein designated panaxagin with ribonuclease activity, but possessing a sequence distinct from ribonucleases previously reported from ginseng calluses, was isolated. The purification protocol employed comprised extraction with cold saline, (NH4)2SO4 precipitation, ion exchange chromatography on DEAE-cellulose, affinity chromatography on Affi-gel blue gel, ion exchange chromatography on SP-Sepharose, and gel filtration on Superdex 75 by fast protein liquid chromatography. The purified protein was composed of two identical subunits each with a molecular weight of 26 $\mathrm{kDa}$. Its N-terminal amino acid sequence exhibits sites of similarity with the sequences of plant ribosome inactivating proteins and fungal ribonucleases. The spectrum of biological activities of panaxagin encompassed ribonuclease activity toward yeast transfer RNA, translation-inhibitory activity in a rabbit reticulocyte lysate system, and antifungal activity against fungi including coprinus comatus and Fusarium oxysporum, but not against Rhizoctonia solani. 
Therapeutic impacts of Indian and Korean ginseng on human beings

Table 1 Comparative analysis of Indian and Korean ginseng (continued)

\begin{tabular}{|c|c|c|}
\hline $\begin{array}{l}\text { Therapeutic } \\
\text { effects }\end{array}$ & Indian ginseng & Korean ginseng \\
\hline $\begin{array}{l}\text { Anti-fungal } \\
\text { activity }\end{array}$ & & $\begin{array}{l}\text { In addition it displayed an inhibitory } \\
\text { activity against human } \\
\text { immunodeficiency virus reverse } \\
\text { transcriptase and succinylation } \\
\text { augmented this activity ( } \mathrm{Ng} \text { and Wang, } \\
2001) \text {. }\end{array}$ \\
\hline $\begin{array}{l}\text { Immune } \\
\text { enhancing } \\
\text { activity }\end{array}$ & $\begin{array}{l}\text { This study to investigate the } \\
\text { immunoregulation action of Indian } \\
\text { ginseng root extract (IRRE) in } \\
\text { immunodeficiency mice. } \\
\text { Immunodeficiency mice were fed } \\
\text { IRRE with doses of } 5,2.5 \text {, } \\
0.85 \mathrm{~g} \times \mathrm{kg}(-1) \text { for } 15 \text { days before } \\
\text { their immune function were } \\
\text { observed. IRRE could relieve } \\
\text { retarded growth and viscera index } \\
\text { drop of mice induced by CP, could } \\
\text { heighten the response of delayed } \\
\text { hypersensitivity and the amount of } \\
\text { antibody in serum. The proliferation } \\
\text { of ConA-induced mitogenic response } \\
\text { for spleen lymphocyte was also } \\
\text { increased, compared with the CP } \\
\text { group }(P<0.05) \text {. IRRE could } \\
\text { enhance the content of marrow DNA } \\
\text { and NO of serum with no change of } \\
\text { acid phosphatase and alkalinity } \\
\text { phosphatase. IRRE could enhance the } \\
\text { phagocytosis of celiac macrophage, } \\
\text { protect the spleen from damage and } \\
\text { improve marrow inhibition in } \\
\text { immunodeficiency mice (Zhou and } \\
\text { Zhang, } 2008 \text { ). }\end{array}$ & $\begin{array}{l}\text { This study was conducted to investigate } \\
\text { the effects of daily consumption of a } \\
\text { standardised ginsenoside-containing } \\
\text { North American ginseng (Panax } \\
\text { quinquefolius) extract on immune } \\
\text { function before, during, and after a } \\
\text { moderate-exercise protocol in healthy } \\
\text { sedentary men. Ten healthy males were } \\
\text { randomised to receive either ginseng } \\
\text { (1125 mg.d-1) or placebo for } 35 \text { days. } \\
\text { After a three month washout period, } \\
\text { subjects received the opposite treatment } \\
\text { for another } 35 \text { days. An exercise test } \\
\text { and blood collection was performed at } \\
\text { the end of each treatment period. } \\
\text { Immune parameters and blood hormone } \\
\text { levels were measured before, during, } \\
\text { and after the exercise stress protocol. } \\
\text { Ginseng treatment reduced the } \\
\text { peripheral blood concentration of } \\
\text { CD8+ T cells and increased } \\
\text { mitogen-stimulated T cell production of } \\
\text { interleukin- } 2 \text { ex vivo. Ginseng had no } \\
\text { effect on total white blood cell counts; } \\
\text { on concentrations of neutrophils, } \\
\text { monocytes, or lymphocytes (CD3+, } \\
\text { CD4+, CD16+, CD20+); on lymphocyte } \\
\text { proliferation; or on neutrophil oxidative } \\
\text { burst. Ginseng did not significantly } \\
\text { affect exercise-induced changes in } \\
\text { plasma concentrations of lactate, } \\
\text { insulin, cortisol, or growth hormone. } \\
\text { The consumption of ginseng for five } \\
\text { weeks had a limited effect on the } \\
\text { immune response to an acute exercise } \\
\text { protocol (Biondo et al., } 2008 \text { ). }\end{array}$ \\
\hline
\end{tabular}

\section{Ginseng-drug interactions and adverse effects of ginsengs}

The intestinal bacterial metabolites of ginsenosides are responsible for the main pharmacological activities of ginseng. The study was to find whether these metabolites influence hepatic metabolic enzymes and to predict the potential for ginseng-prescription drug interactions. Utilising the probe reaction of CYP3A activity, testosterone 
6beta-hydroxylation, the effects of derivatives of 20(S)-PPD and 20(S)-PPT families on CYP3A activity in rat liver microsomes were assayed. Our results showed that ginsenosides from the 20(S)-PPD and 20(S)-PPT family including Rb1, Rb2, Rc, Compound-K, Re, and $\operatorname{Rg} 1$ had no inhibitory effect, whereas Rg2, 20(S)-panaxatriol and 20(S)-protopanaxatriol exhibited competitive inhibitory activity against CYP3A activity in these microsomes with the inhibition constants (Ki) of $86.4+/-0.8$ microM, $1.7+/-0.1$ microM, and 3.2+/-0.2 microM, respectively. This finding demonstrates that differences in their chemical structure might influence the effects of ginsenosides on CYP3A activity and that ginseng-derived products might have potential for significant ginseng-drug interactions (Liu et al., 2004). Herbal medicines are widely consumed by patients in different clinical settings in the USA and all over the world. In this study, seven herbal components ginsenosides $\mathrm{Rb} 1, \mathrm{Rb} 2, \mathrm{Rc}$, and $\mathrm{Rd}$ (from ginseng quercetin) ginkgolides $\mathrm{A}$ and $\mathrm{B}$ (from ginkgo biloba) were investigated for their inhibitory effects on hepatic CYP2C9 and CYP3A4 catalytic activities in human liver microsomes. Tolbutamide 4-methylhydroxylation and testosterone 6beta-hydroxylation were used as index reactions of CYP2C9 or CYP3A4 catalytic activities, respectively. The metabolites of both reactions were measured by high-performance liquid chromatography and used as indicators of whether enzymes were inhibited or unaffected by these agents. Herbal components were studied at various concentrations $(0.1,1,10,100,200 \mathrm{micromol} / \mathrm{L})$. The herbal compounds investigated were capable of inhibiting CYP2C9 and CYP3A4 catalytic activities, but the potencies differed. Quercetin showed marked inhibitory effects on both tolbutamide 4-methylhydroxylation and testosterone 6beta-hydroxylation with IC(50) values of 35 and $38 \mathrm{micromol} / \mathrm{L}$, respectively. Ginsenoside $\mathrm{Rd}$ also had significant inhibitory potency on both CYP2C9- and CYP3A4-mediated index reactions with $\mathrm{IC}(50)$ values of 105 and 62 micromol/L, respectively. Ginsenosides Rb1, Rb2, and Rc had limited inhibitory activities on both enzyme reaction systems, whereas the effects of ginkgolides $\mathrm{A}$ and $\mathrm{B}$ appeared negligible. It is concluded that the components of ginseng and ginkgo biloba screened are capable of inhibiting CYP2C9- and CYP3A4-mediated metabolic reactions (He and Edeki, 2004).

Ginsenosides, or ginseng saponins, are biologically active ingredients of Panax ginseng. Accumulating evidence suggests that ginsenosides can alleviate pain from injections of noxious chemicals, such as capsaicin. In this study we examined the effects of ginsenoside Rc on the capsaicin-induced inward current in Xenopus oocytes that expresses the vanilloid receptor 1 (VR1). Ginsenoside Rc enhanced the capsaicin-induced inward current in a concentration-dependent and reversible manner, but ginsenoside Rc itself elicited no membrane currents. The VR1 antagonist capsazepine almost completely blocked the inward current that was elicited by capsaicin plus ginsenoside Rc. Tested the effect of seven other fractionated ginsenosides (i.e., Rb1, Rb2, Rd, Re, Rf, Rg1, and Rg2) in addition to ginsenoside Rc. They found that six of them significantly enhanced the inward current that is induced by capsaicin with the following order of potency: $\mathrm{Rc}>\mathrm{Rf}>\mathrm{Rg} 1$ approximately $\mathrm{Rd}>\mathrm{Rb} 2>\mathrm{Rb} 1$. These results show the possibility that the in vivo effect of ginsenosides against capsaicin-induced pain is derived from their modulation of the VR1 channel function (Jung et al., 2001). A 26-year-old man with CML who had taken imatinib $400 \mathrm{mg}$ daily for seven years with no complications presented with right upper quadrant pain. Laboratory test results included alanine aminotransferase 1,069 U/L, aspartate aminotransferase $481 \mathrm{U} / \mathrm{L}$, alkaline phosphatase $124 \mathrm{IU} / \mathrm{L}$, total bilirubin $1.4 \mathrm{mg} / \mathrm{dL}$, albumin $4.0 \mathrm{~g} / \mathrm{dL}$, and international normalised ratio 
1.08. Liver biopsy showed acute lobular hepatitis favouring a drug-induced etiology, and a diagnosis of imatinib-induced hepatotoxicity was made. The patient's only lifestyle modification prior to the diagnosis of hepatotoxicity was daily ingestion of Panax ginseng via energy drinks for the past three months. Both imatinib and ginseng were discontinued, and the patient was treated with a short course of corticosteroids. Imatinib was later restarted at the same dose with no recurrent elevations in his liver enzyme levels. Imatinib-associated hepatotoxicity usually presents within one to two years of therapy initiation, with the median time to hepatotoxicity being 100 days. Ginseng is an herb that is not known to be hepatotoxic. In vivo, ginseng is known to inhibit CYP3A4, the primary enzyme involved in the metabolism of imatinib. We propose that our patient's late-onset imatinib-associated hepatotoxicity was due to an interaction between ginseng and imatinib through CYP3A4. Based on the Naranjo probability scale, it is probable that imatinib caused this patient's hepatotoxicity, and the Horn drug interaction probability scale also indicates a probable interaction between imatinib and ginseng. This case emphasises the importance of continuous monitoring of liver function tests even after several years of imatinib therapy and the importance of advising patients to avoid ginseng and any other over-the-counter herbal supplements that may interact with imatinib (Bilgi et al., 2010).

If we are currently being treated with any of the following medications, we should not use ginseng without first talking to your healthcare provider:

1 ACE inhibitors: Asian ginseng may interact with angiotensin-converting enzyme (ACE) inhibitors. These medications include: Captopril, Benazepril, Enalapril, Lisinopril, Fosinopril, Ramipril, Perindopril, Quinapril, Moexipril and Trandolapril

2 Calcium channel blockers: Asian ginseng may alter the effects of certain heart medications, including calcium channel blockers. These medications include: Amlodipine, Diltiazem and Nifedipine.

3 Blood thinning medications (anticoagulants): Asian ginseng may decrease the effectiveness of the blood-thinning medication warfarin. In addition, ginseng may inhibit platelet activity. For this reason, it should probably not be used with aspirin.

4 Caffeine: Ginseng may increase the stimulant effect of caffeine, possibly causing nervousness, sweating, insomnia, or irregular heartbeat.

5 Diabetes medications: Ginseng may lower blood sugar levels, increasing the risk of hypoglycemia (low blood sugar).

6 Stimulants: Ginseng may increase the stimulant effect and side effects of some medications take for attention deficit hyperactivity disorder, including amphetamine and dextroamphetamine and methylphenidate.

7 Monoamine oxidase inhibitors (MAOIs): Ginseng may increase the risk of mania when taken with MAOIs, a type of antidepressant. There have been reports of interaction of ginseng with phenelzine, Isocarboxazid, Phenelzine and Tranylcypromine causing headaches, tremors, and mania.

8 Morphine: Asian ginseng may block the painkilling effects of morphine. 


\section{Standardisation}

The major pharmacologically active ingredients of ginsengs are ginsenosides whose chemical profiles can change with temperature and steaming process. The manufacturing process may also alter the quantities of ginsenosides. Lot to lot variation in the biologically active ingredients may occur in different ginsengs. So the ingredients of various ginsengs are standardised by character loss on drying $\mathrm{pH}$ ash, heavy metals total residual organic solvents, total aerobic microbial count, and quantity of presence fungi, staph aureus, salmonellaabsen and E. coli.

\section{Conclusions}

In Ayurveda, Withania somnifera and Panax ginseng are considered a rasayana herb. Both herbs are producing more or less, similar therapeutic actions on human beings. Withania somnifera is one of the versatile ayurvedic herbal remedies with adaptogenic, anti-stress, anti-anxiety, antioxidant, anticancer, immunity enhancing, rejuvenating and fertility and stamina enhancing properties. But, in the case of Panax ginseng, the ginsenosides have more dominant curative against lung and colorectal cancer. Both are benefits to our system in so many different ways that it will be better to use the word 'versatile herbs' for this botanical of ayurvedic medicine. Both are powerful Rasayanas, meaning that it acts as an overall tonic for greater vitality and longevity. That will be good to consider both traditional and ayurvedic properties and modern clinical herbal research approved benefits.

\section{Acknowledgements}

This project has been funded in part with Federal funds from SASTRA University.

\section{References}

Ahuja, A., Kaur, D., Sharada, M., Kumar, A., Suri, K.A. and Dutt, P. (2009) 'Glycowithanolides accumulation in vitro shoot cultures of Indian ginseng (Withania somnifera Dunal)', Nat. Prod. Commun., Vol. 4, No. 4, pp.479-482.

Bi, X., Zhao, Y., Fang, W. and Yang, W. (2009) 'Anticancer activity of Panax notoginseng extract 20(S)-25-OCH3-PPD: targeting beta-catenin signalling', Clin. Exp. Pharmacol. Physiol., Vol. 36, No. 11, pp.1074-1078.

Bilgi, N., Bell, K., Ananthakrishnan, A.N. and Atallah, E. (2010) 'Imatinib and Panax ginseng: a potential interaction resulting in liver toxicity', Ann Pharmacother, Vol. 44, No. 5, pp.926-928.

Biondo, P.D., Robbins, S.J., Walsh, J.D., McCargar, L.J., Harber, V.J. and Field, C.J. (2008) 'A randomized controlled crossover trial of the effect of ginseng consumption on the immune response to moderate exercise in healthy sedentary men', Appl. Physiol. Nutr. Metab., Vol. 33, No. 5, pp.966-975.

Chae, S., Kang, K.A., Chang, W.Y., Kim, M.J., Lee, S.J., Lee, Y.S., et al. (2009) 'Effect of compound $\mathrm{K}$, a metabolite of ginseng saponin, combined with gamma-ray radiation in human lung cancer cells in vitro and in vivo', J. Agric. Food Chem., Vol. 57, No. 13, pp.5777-5782. 
Chaurasiya, N.D., Sangwan, R.S., Misra, L.N., Tuli, R. and Sangwan, N.S. (2009) 'Metabolic clustering of a core collection of Indian ginseng Withania somnifera Dunal through DNA, isoenzyme, polypeptide and withanolide profile diversity', Fitoterapia, Vol. 80, No. 8, pp.496-505.

Dua, P.R., Shanker, G., Srimal, R.C., Saxena, K.C., Saxena, R.P., Puri, A., et al. (1989) 'Adaptogenic activity of Indian Panax pseudoginseng', Indian J. Exp. Biol., Vol. 27, No. 7, pp.631-634.

Grandhi, A., Mujumdar, A.M. and Patwardhan, B. (1994) 'A comparative pharmacological investigation of Ashwagandha and Ginseng', J. Ethnopharmacol., Vol. 44, No. 3, pp.131-135.

He, N. and Edeki, T. (2004) 'The inhibitory effects of herbal components on CYP2C9 and CYP3A4 catalytic activities in human liver microsomes', Am. J. Ther., Vol. 11, No. 3, pp.206-212.

Hong, B., Ji, Y.H., Hong, J.H., Nam, K.Y. and Ahn, T.Y. (2002) 'A double-blind crossover study evaluating the efficacy of Korean red ginseng in patients with erectile dysfunction: a preliminary report', Journal of Urology, Vol. 168, No. 5, pp.20-21.

Ichikawa, H., Takada, Y., Shishodia, S., Jayaprakasam, B., Nair, M.G. and Aggarwal, B.B. (2006) 'Withanolides potentiate apoptosis, inhibit invasion, and abolish osteoclastogenesis through suppression of nuclear factor-kappaB (NF-kappaB) activation and NF-kappaB-regulated gene expression', Mol. Cancer Ther., Vol. 5, No. 6, pp.1434-1445.

Iuvone, T., Esposito, G., Capasso, F. and Izzo, A.A. (2003) 'Induction of nitric oxide synthase expression by Withania somnifera in macrophages', Life Sci., Vol. 72, No. 14, pp.1617-1625.

Jung, S.Y., Choi, S., Ko, Y.S., Park, C.S., Oh, S., Koh, S.R., et al. (2001) 'Effects of Ginsenosides on vanilloid receptor (VR1) channels expressed in xenopus oocytes', Molecules and Cells, Vol. 12, No. 3, pp.342-346.

Kim, Y.J., Lee, J.H., Jung, D.J., Gayathri, S., Shim, J.S., In, J.G., et al. (2009) 'Isolation and characterization of pathogenesis-related protein 5 (PgPR5) gene from panax ginseng', The Plant Pathology Journal, Vol. 25, No. 4, pp.303-440.

Kulkarni, S.K. and Dhir, A. (2008) 'Withania somnifera: an Indian ginseng', Prog. Neuropsychopharmacol. Biol. Psychiatry, Vol. 32, No. 5, pp.1093-1105.

Lee, M.S., Hwang, J.T., Kim, S.H., Yoon, S., Kim, M.S., Yang, H.J., et al. (2010) 'Ginsenoside Rc, an active component of panax ginseng, stimulates glucose uptake in $\mathrm{C} 2 \mathrm{C} 12$ myotubes through an AMPK-dependent mechanism', Journal of Ethnopharmacology, Vol. 127, No. 3, pp.771-776.

Lin, Y.L., Huang, C.L., Lee, Y.C., Liao, W.C., Lai, W.L., Lin, Y.J. et al. (2009) 'Mechanisms of panax ginseng in preventing rat pheochromocytoma cells from apoptosis', J. Ethnopharmacol., Vol. 125, No. 1, pp.10-15.

Liu, N., Piao, H.R. and Zhao, Y.Q. (2009) 'Preparation and isolation on the rare ginsenoside derivatives with anti-cancer activity', Zhong Yao Cai, Vol. 32, No. 5, pp.707-709.

Liu, Y., Li, W., Li, P., Deng, M.C., Yang, S.L. and Yang, L. (2004) 'The inhibitory effect of intestinal bacterial metabolite of ginsenosides on CYP3A activity', Biol. Pharm. Bull., Vol. 27, No. 10, pp.1555-1560.

Lu, Z.F., Shen, Y.X., Zhang, P., Xu, Y.J., Fan, Z.H., Cheng, M.H., et al. (2010) 'Ginsenoside Rg1 promotes proliferation and neurotrophin expression of olfactory ensheathing cells', J. Asian Nat. Prod. Res., Vol. 12, No. 4, pp.265-272.

Murthy, H.N., Dijkstra, C., Anthony, P., White, D.A., Davey, M.R., Power, J.B., et al. (2008) 'Establishment of Withania somnifera hairy root cultures for the production of withanolide A', J. Integr. Plant Biol., Vol. 50, No. 8, pp.975-981.

Muruganandam, A.V., Kumar, V. and Bhattacharya, S.K. (2002) 'Effect of poly herbal formulation, EuMil, on chronic stress-induced homeostatic perturbations in rats', Indian J. Exp. Biol., Vol. 40, No. 10, pp.1151-1160. 
Ng, F., Yun, H., Lei, X., Danishefsky, S.J., Fahey, J., Stephenson, K., et al. (2008) '(3R, 9R, 10R)-Panaxytriol: a molecular-based nutraceutical with possible application to cancer prevention and treatment', Tetrahedron Lett., Vol. 49, No. 50, pp.7178-7179.

Ng, T.B. and Wang, H. (2001) 'Panaxagin, a new protein from Chinese ginseng possesses anti-fungal, anti-viral, translation-inhibiting and ribonuclease activities', Life Sci., Vol. 68, No. 7, pp.739-749.

Panda, S. and Kar, A. (1998) 'Changes in thyroid hormone concentrations after administration of ashwagandha root extract to adult male mice', J. Pharm. Pharmacol., Vol. 50, No. 9, pp.1065-1068.

Panda, S. and Kar, A. (1999) 'Withania somnifera and Bauhinia purpurea in the regulation of circulating thyroid hormone concentrations in female mice', J. Ethnopharmacol., Vol. 67, No. 2, pp.233-239.

Parvin, S., Kim, Y.J., Pulla, R.K., Sathiyamoorthy, S., Miah, M.G., Wasnik, N.G., et al. (2010) 'Identification and characterization of spermidine synthase gene from Panax ginseng', Mol. Biol. Rep., Vol. 37, No. 2, pp.923-932.

RajaSankar, S., Manivasagam, T., Sankar, V., Prakash, S., Muthusamy, R., Krishnamurti, A., et al. (2009) 'Withania somnifera root extract improves catecholamines and physiological abnormalities seen in a Parkinson's disease model mouse', J. Ethnopharmacol., Vol. 125, No. 3, pp.369-373.

Sathiyamoorthy, S., In, J.G., Gayathri, S., Kim, Y.J. and Yang, D. (2010a) 'Gene ontology study of methyl jasmonate-treated and non-treated hairy roots of Panax ginseng to identify genes involved in secondary metabolic pathway', Genetika, Vol. 46, No. 7, pp.932-939.

Sathiyamoorthy, S., In, J.G., Gayathri, S., Kim, Y.J. and Yang, D.C. (2010b) 'Generation and gene ontology based analysis of expressed sequence tags (EST) from a Panax ginseng C.A. Meyer roots', Mol. Biol. Rep., Vol. 37, No. 7, pp.3465-3472.

Sathiyaraj, G., Srinivasan, S., Subramanium, S., Kim, Y.J., Kwon, W.S. and Yang, D.C. (2010) 'Polygalacturonase inhibiting protein: isolation, developmental regulation and pathogen related expression in Panax ginseng C.A. Meyer', Mol. Biol. Rep., Vol. 37, No. 7, pp.3445-3454.

Schliebs, R., Liebmann, A., Bhattacharya, S.K., Kumar, A., Ghosal, S. and Bigl, V. (1997) 'Systemic administration of defined extracts from Withania somnifera (Indian Ginseng) and Shilajit differentially affects cholinergic but not glutamatergic and GABAergic markers in rat brain', Neurochem. Int., Vol. 30, No. 2, pp.181-190.

Singh, B., Chandan, B.K. and Gupta, D.K. (2003) 'Adaptogenic activity of a novel withanolide-free aqueous fraction from the roots of Withania somnifera Dun, (Part II)', Phytother Res., Vol. 17, No. 5, pp.531-536.

Singh, B., Saxena, A.K., Chandan, B.K., Gupta, D.K., Bhutani, K.K. and Anand, K.K. (2001) 'Adaptogenic activity of a novel, withanolide-free aqueous fraction from the roots of Withania somnifera Dun', Phytother Res., Vol. 15, No. 4, pp.311-318.

Suh, S.O., Kroh, M., Kim, N.R., Joh, Y.G. and Cho, M.Y. (2002) 'Effects of red ginseng upon postoperative immunity and survival in patients with stage III gastric cancer', Am. J. Chin. Med., Vol. 30, No. 4, pp.483-494.

Sun, X.B., Matsumoto, T., Kiyohara, H., Hirano, M. and Yamada, H. (1991) 'Cytoprotective activity of pectic polysaccharides from the root of Panax ginseng', J. Ethnopharmacol., Vol. 31, No. 1, pp.101-107.

Ven Murthy, M.R., Ranjekar, P.K., Ramassamy, C. and Deshpande, M. (2010) 'Scientific basis for the use of Indian Ayurvedic medicinal plants in the treatment of neurodegenerative disorders: Ashwagandha', Central Nervous Systems Agents, Vol. 10, No. 3, pp.238-246.

Wang, C.Z. and Yuan, C.S. (2008) 'Potential role of ginseng in the treatment of colorectal cancer', Am. J. Chin. Med., Vol. 36, No. 6, pp.1019-1028. 
Wang, H., Sun, H., Kwon, W.S., Jin, H. and Yang, D.C. (2010) 'A PCR-based SNP marker for specific authentication of Korean ginseng (Panax ginseng) cultivar 'Chunpoong', Mol. Biol. Rep., Vol. 37, No. 2, pp.1053-1057.

Wang, W., Rayburn, E.R., Hang, J., Zhao, Y., Wang, H. and Zhang, R. (2009) 'Anti-lung cancer effects of novel ginsenoside 25-OCH (3)-PPD', Lung Cancer, Vol. 65, No. 3, pp.306-311.

Wargovich, M.J. (2001) 'Colon cancer chemoprevention with ginseng and other botanicals', $J$. Korean Med. Sci., Vol. 16, pp.S81-S86.

Yan, Z., Zhu, Z.L., Wang, H.Q., Li, W., Mi, Y.X. and Liu, C.X. (2010) 'Pharmacokinetics of panaxatriol disuccinate sodium, a novel anti-cancer drug from Panax notoginseng, in healthy volunteers and patients with advanced solid tumors', Acta Pharmacol. Sin., Vol. 31, No. 11, pp.1515-1522.

Yang, M., Wang, B.X., Jin, Y.L., Wang, Y. and Cui, Z.Y. (1990) 'Effects of ginseng polysaccharides on reducing blood glucose and liver glycogen', Zhongguo Yao Li Xue Bao, Vol. 11, No. 6, pp.520-524.

Yoon, S.R., Lee, G.D., Park, J.H., Lee, I.S. and Kwon, J.H. (2010) 'Ginsenoside composition and antiproliferative activities of explosively puffed ginseng (Panax ginseng C.A. Meyer)', $J$. Food Sci., Vol. 75, No. 4, pp.C378-C382.

Yun, T.K., Lee, Y.S., Lee, Y.H., Kim, S.I. and Yun, H.Y. (2001) 'Anticarcinogenic effect of Panax ginseng C.A. Meyer and identification of active compounds', J. Korean Med. Sci., Vol. 16 pp.S6-S18.

Yun, T.K., Zheng, S., Choi, S.Y., Cai, S.R., Lee, Y.S., Liu, X.Y., et al. (2010) 'Non-organ-specific preventive effect of long-term administration of Korean red ginseng extract on incidence of human cancers', J. Med. Food, Vol. 13, No. 3, pp.489-494.

Zhang, J.H., Wang, J.P. and Wang, H.J. (2007) 'Clinical study on effect of total Panax notoginseng saponins on immune related inner environment imbalance in rheumatoid arthritis patients', Zhongguo Zhong Xi Yi Jie He Za Zihi, Vol. 27, No. 7, pp.589-592.

Zhou, C.Q. and Zhang, Y. (2008) 'Immunomodulatory effect of Indian ginseng root extract on immunodeficiency mice', Zhongguo Zhong Yao Za Zhi, Vol. 33, No. 16, pp.2014-2018. 